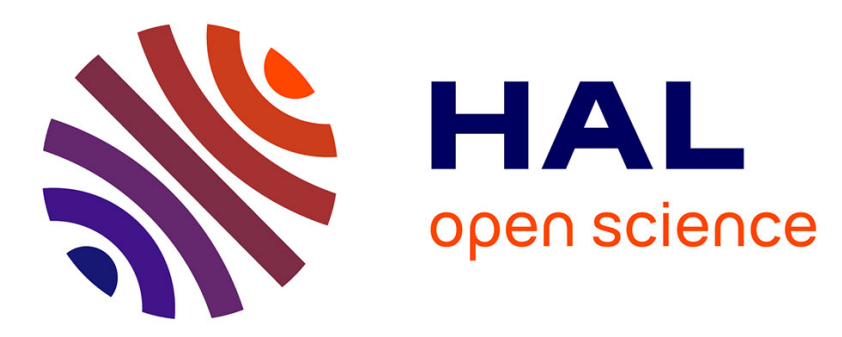

\title{
Activation of NADPH oxidase is the primary trigger of epileptic seizures in rodent models
}

Anton Malkov, Anton I Ivanov, Alexandra Latyshkova, Piotr Bregestovski, Misha Zilberter, Yuri Zilberter

\section{- To cite this version:}

Anton Malkov, Anton I Ivanov, Alexandra Latyshkova, Piotr Bregestovski, Misha Zilberter, et al.. Activation of NADPH oxidase is the primary trigger of epileptic seizures in rodent models. Annals of Neurology, In press, 10.1002/ana.25474 . hal-02089135

\section{HAL Id: hal-02089135 https://hal.science/hal-02089135}

Submitted on 3 Apr 2019

HAL is a multi-disciplinary open access archive for the deposit and dissemination of scientific research documents, whether they are published or not. The documents may come from teaching and research institutions in France or abroad, or from public or private research centers.
L'archive ouverte pluridisciplinaire HAL, est destinée au dépôt et à la diffusion de documents scientifiques de niveau recherche, publiés ou non, émanant des établissements d'enseignement et de recherche français ou étrangers, des laboratoires publics ou privés. 
Activation of NADPH oxidase is the primary trigger of epileptic seizures in rodent models

Anton Malkov, Ph.D. ${ }^{1,2^{*}}$, Anton I. Ivanov, Ph.D. ${ }^{1^{*}}$, Alexandra Latyshkova ${ }^{2}$, Piotr Bregestovski, Ph.D. ${ }^{1,3}$, Misha Zilberter, Ph.D. ${ }^{4}$, Yuri Zilberter, Ph.D. ${ }^{1} \dagger$

1. Aix Marseille Université, Inserm, INS UMR_S 1106, 13005, Marseille, France

2. Institute of Theoretical and Experimental Biophysics, Russian Academy of Sciences, 142290, Pushchino, Russia

3. Institute of Neurosciences, Kazan State Medical University, Kazan, Russia

4. Gladstone Institute of Neurological Disease, CA 94158-2261, San Francisco, USA

$*$ contributed equally $\dagger$ corresponding author: yuri.zilberter@univ-amu.fr

\begin{abstract}
Objective: Despite decades of epilepsy research, $30 \%$ of focal epilepsies remain resistant to anti-seizure drugs, with effective drug development impeded by lack of understanding on how seizures are initiated. Here we report the mechanism of seizure onset relevant to most seizures characteristic for focal epilepsies.

Methods: Electric and metabolic network parameters were measured using several seizure models in mouse hippocampal slices and acutely-induced seizures in rats in-vivo to determine metabolic events occuring at seizure onset.

Results: We show that the seizure onset is associated with a rapid release of $\mathrm{H}_{2} \mathrm{O}_{2}$ resulting from NMDA receptor-mediated activation of NADPH oxidase (NOX). NOX blockade prevented the fast $\mathrm{H}_{2} \mathrm{O}_{2}$ release as well as the DC shift and seizure-like event induction in slices. Similarly, intracerebroventricular injection of NOX antagonists prevented acutely induced seizures in rats. Interpretation: Our results show that seizures are initiated by NMDA receptor-mediated NOX-induced oxidative stress and can be arrested by NOX inhibition. We introduce a novel use for blood-brain barrier-permeable NOX inhibitor with a significant potential to become the first seizure-specific medication. Thus, targeting NOX may provide a breakthrough treatment for focal epilepsies.
\end{abstract}

This article has been accepted for publication and undergone full peer review but this current version is the author version which may lead to differences between this version and the Version of Record. Please cite this article as an 'Accepted Article', doi: 10.1002/ana.25474 


\section{Introduction}

A major goal of contemporary epilepsy research is the discovery of therapies that would prevent the development of recurrent seizures in individuals at risk. However, despite the availability of at least 22 anti-seizure drugs (1), about $30 \%$ of patients with epilepsy remain resistant to drug therapy and continue to have seizures (2). Moreover, the proportion of those not becoming seizure-free despite treatment has not decreased substantially over the past 50 years (3). A lack of knowledge on molecular mechanism of seizure initiation impedes the development of targeted seizure therapy and modern anti-seizure drugs therefore mostly target general brain excitability (4).

In patients with temporal lobe epilepsy, clinical intracranial EEG recordings using DC-coupled amplifiers revealed two major distinct EEG seizure onset patterns characterized by hypersynchronous or low voltage fast activity (LVF), each likely underlined by distinct pathological mechanisms (5). The low voltage fast activity pattern occurs in majority of seizures and often starts with a high-amplitude spike (sentinel spike) followed by a pronounced DC shift (6-11). Similar seizure onset was also reported for most ex vivo animal models using various seizure-inducing protocols (12-14), for human brain slices (15-17) and for in vivo acute and chronic animal models (18). The critical issue for understanding the seizure onset is what processes associated with the sentinel spike may trigger the following DC shift and the subsequent seizure. To address this question, we simultaneously measured electric (local field potentials, LFPs) and metabolic (extracellular oxygen, glutamate, $\mathrm{H}_{2} \mathrm{O}_{2}$ ) network parameters in hippocampal slices using several in vitro seizure models and verified the results in vivo in rats.

\section{Methods}

All animal protocols and experimental procedures were approved by the INSERM Ethics Committee for Animal Experimentation (\#30-03102012).

\section{Tissue slice preparation}

Ex-vivo local field potential (LFP) recordings were performed on brain slices from P21-56 OF1 male mice (Charles River Laboratories, France). A mouse anaesthetized with isoflurane was decapitated; the brain was rapidly removed from the skull and placed in the ice-cold ACSF. The ACSF solution consisted of (in mmol/L): $\mathrm{NaCl} 126, \mathrm{KCl} 3.50, \mathrm{NaH}_{2} \mathrm{PO}_{4} 1.25, \mathrm{NaHCO}_{3} 25, \mathrm{CaCl}_{2} 2.00, \mathrm{MgCl}_{2} 1.30$, and dextrose 5, pH 7.4. ACSF was aerated with 95\% O2/5\% CO2 gas mixture. Sagittal slices $(350 \mu \mathrm{m})$ were cut using a tissue slicer (Leica VT 1200s, Leica Microsystem, Germany). During cutting, slices were submerged in an ice-cold $\left(<6^{\circ} \mathrm{C}\right)$ solution consisting of (in mmol/L): K-gluconate 140, HEPES 10, Na-gluconate 15, EGTA 0.2, $\mathrm{NaCl} 4$, pH adjusted to 7.2 with $\mathrm{KOH}$. Slices were immediately transferred to a multi-section, dual-side perfusion holding chamber with constantly circulating ACSF and allowed to recover for $2 \mathrm{~h}$ at room temperature $\left(22^{\circ} \mathrm{C}-24^{\circ} \mathrm{C}\right)$.

\section{Synaptic stimulation and field potential recordings}

Slices were transferred to a recording chamber continuously superfused $(10 \mathrm{ml} / \mathrm{min})$ with ACSF $\left(33-34^{\circ} \mathrm{C}\right)$ with access to both slice sides. Schaffer collateral/commissures was stimulated using the DS2A isolated stimulator (Digitimer Ltd, UK) with a bipolar metal electrode. Stimulus current was adjusted using single pulses $(40-170 \mu \mathrm{A}, 200 \mu \mathrm{s}, 0.15 \mathrm{~Hz})$ to induce a LFP of about $50 \%$ maximal amplitude. LFPs were recorded using glass microelectrodes filled with ASCF, placed in stratum 
pyramidale of CA1 area and connected to the ISO DAM-8A amplifier (WPI, FL). Synaptic stimulation consisted of a stimulus train $(200 \mu$ s pulses $)$ at $100 \mathrm{~Hz}$ lasting $1 \mathrm{~s}$.

\section{Oxygen, glutamate and $\mathrm{H}_{2} \mathrm{O}_{2}$ measurements}

A Clark-style oxygen microelectrode (Unisense Ltd, Denmark) was used to measure slice tissue $\mathrm{pO}_{2}$, while extracellular $\mathrm{H}_{2} \mathrm{O}_{2}$ was measured with Null sensor (Sarissa Biomedical, Coventry, UK) as described elsewhere 14. Extracellular glutamate was measured using enzymatic microelectrodes (Sarissa Biomedical, Coventry, UK) connected to a free radical analyzer TBR4100 (Word Precision Instruments Ltd, UK).

\section{Pharmacology}

Antagonists of NMDA receptors, (2R)-amino-5-phosphonopentanoate (APV) and kynurenic acid; antagonist of AMPA/kainate receptors, 6-cyano-7-nitroquinoxaline-2,3-dione (CNQX) and GABAA receptors, bicuculline, were purchased from Tocris Bioscience (Bio-Techne Ltd, UK); 4-aminopyridine (4-AP) and Celastrol were purchased from Sigma-Aldrich (Sigma-Aldrich Chimie S.a.r.1.); GSK2795039 from MedChemExpress Europe.

\section{In Vivo Experiments}

19 mature Wistar male rats $(300-400 \mathrm{~g})$ were used for in vivo experiments. Animals were anesthetized with pentobarbital $(35 \mathrm{mg} / \mathrm{kg})$ supplemented with xylazine $(10 \mathrm{mg} / \mathrm{kg})$. Body temperature was kept at $37^{\circ} \mathrm{C}$ using a heating pad. Rats were placed in a stereotaxic frame, scalped and holes for electrodes and guide cannula were drilled. Extracellular nichrome electrode $(\varnothing 25 \mu \mathrm{m})$ was implanted in hippocampal CA1 field (stereotaxic coordinates $\mathrm{AP}=-3.2 \mathrm{~mm}, \mathrm{~L}=2 \mathrm{~mm}, \mathrm{H}=3.5 \mathrm{~mm}$ ), guide cannula for drug injection was implanted just above lateral ventricle $(\mathrm{AP}=0.8 \mathrm{~mm}, \mathrm{~L}=1.7 \mathrm{~mm}, \mathrm{H}=2.3 \mathrm{~mm})$. Stereotaxic coordinates were set according to Paxinos and Watson rat brain atlas (The Rat Brain in Stereotaxic Coordinates, 6th edition). Electrocoagulation was used to verify electrode and cannula placements. Indifferent electrode was screwed into occipital bone. In experiments with $\mathrm{H}_{2} \mathrm{O}_{2}$ sensor, additional cranial window (Ø $\left.2 \mathrm{~mm}\right)$ above contralateral hippocampus was drilled and sensor was dipped in hippocampus $(3.5 \mathrm{~mm})$ using stereotaxic manipulator. After surgical preparation, the cortex was kept under saline to prevent drying. Stereotaxic frame was transferred to electrophysiological setup and recordings started. LFPs were amplified (Grass Instrument, U.S.A.), filtered (high-pass filter $0.01 \mathrm{~Hz}$, digitized at $5 \mathrm{kHz}$ ), and stored using DataPack2k software (RUN Technologies, USA). $\mathrm{H}_{2} \mathrm{O}_{2}$ sensor (Sarissa probe) was polarized $+500 \mathrm{mV}$ and recorded using potentiostat (Diamond Electrotech). Following $10 \mathrm{~min}$ recordings of control activity either $7 \mu \mathrm{g}$ of 4 -AP in $1 \mu \mathrm{L}$ saline or $0.1 \mu \mathrm{g}$ of kainate (KA) in $2 \mu \mathrm{L}$ was injected i.c.v. using Hamilton syringe to induce seizure activity. After induction of stable seizure activity (at least 1 seizure episode per $5 \mathrm{~min}$, from 30 to $60 \mathrm{~min}$ after 4-AP/KA injection) drugs were injected i.c.v. (APV $4 \mu \mathrm{g}$ in $1 \mu \mathrm{L}$ saline, GSK2795039 $45 \mu \mathrm{g}$ in $1 \mu \mathrm{L}$ DMSO, celastrol $72 \mu \mathrm{g}$ in $2 \mu \mathrm{L}$ DMSO).

For spontaneous seizure detection, we used automated computer analysis of LFP recordings with the following selection limits: seizure threshold $7 *$ RMS (root mean square) of baseline; number of oscillations in a scanning window $(5 \mathrm{~s})$ exceeding the threshold no less than 10; minimal seizure duration $10 \mathrm{~s}$; time interval between seizures no less than $3 \mathrm{~s}$.

For low frequency (DC) shift analysis representative episodes 300s long in each experiment in control, after 4-AP/KA and after drug injection were chosen. LFPs were filtered from 0 to $1 \mathrm{~Hz}$, the average LFP 
amplitude was set as zero and the negative component of LFP was reflected against zero. DC line index was calculated as an area (integral) under resulting curve normalized to control values.

\section{Statistical analysis and signal processing}

Group measures were expressed as means \pm SEM. Statistical significance was assessed using the Wilcoxon's signed paired test and the Wilcoxon Rank-Sum test.

Significance level was set at $\mathrm{p}<0.05$. Correlation between two variables was calculated using Pearson's correlation coefficient (r). Signal analysis was performed using the IgorPro software (WaveMetrics, Inc., USA) with custom developed macros.

\section{Results}

\section{Glutamate-induced activation of NOX triggers seizures in hippocampal slices}

Experiments in acute brain slices were performed using a 4-AP seizure model $(n=36)$ with results

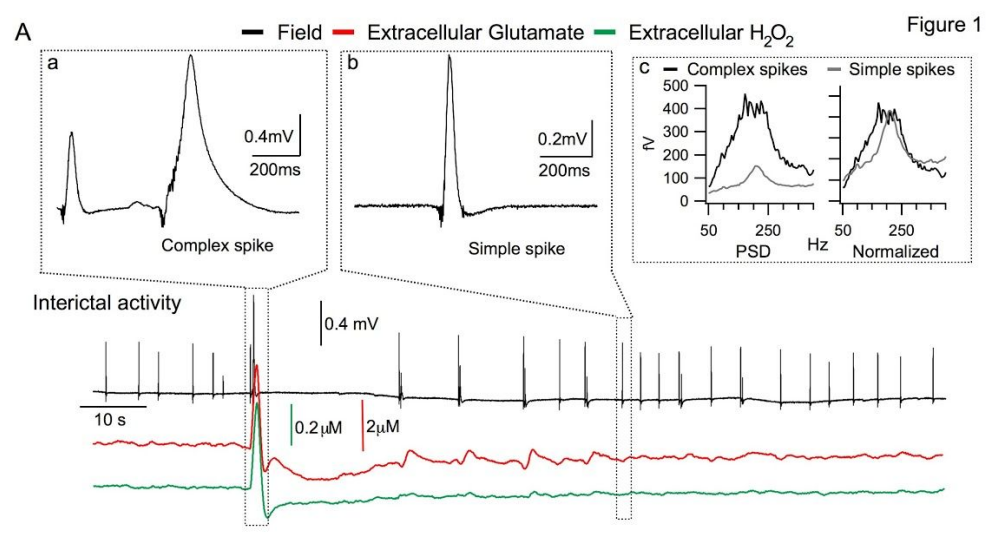

reproduced using bicuculline $(\mathrm{n}=3)$ and

low-Mg $(0.1 \mathrm{mM} ; \mathrm{n}=12)$ seizure models.

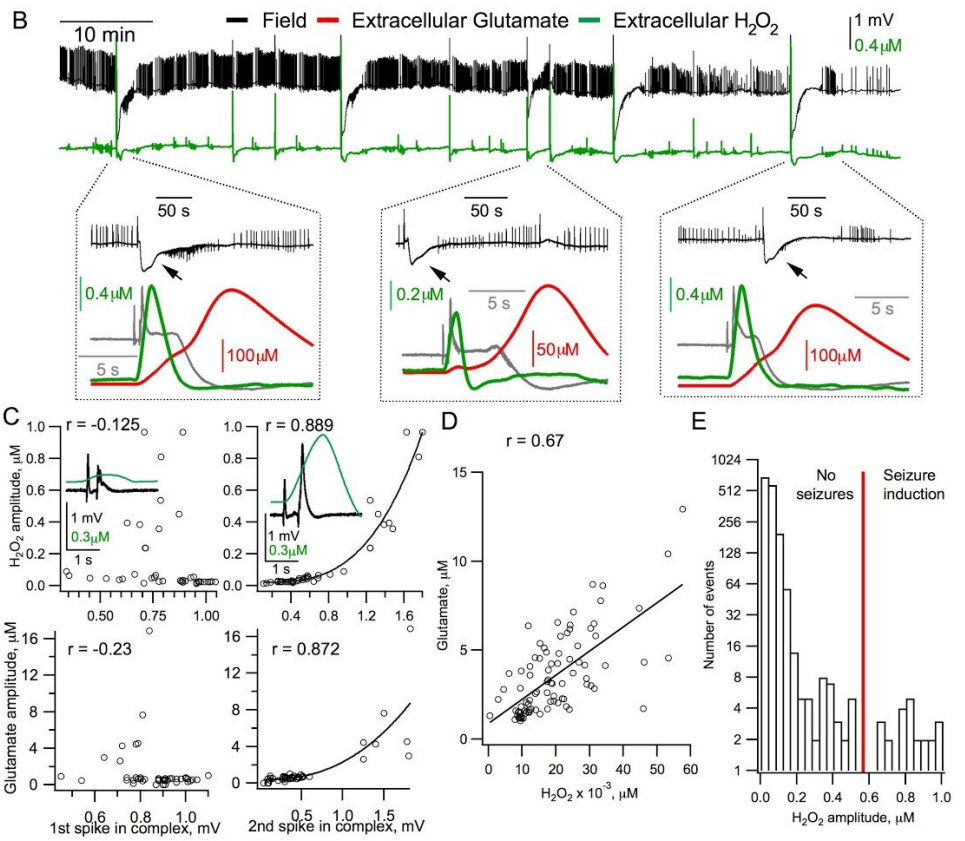

Fig. 1. Extracellular $\mathrm{H}_{2} \mathrm{O}_{2}$ and glutamate during epileptiform activity induced by 4-AP in hippocampal slices.

A. Glutamate release and $\mathrm{H}_{2} \mathrm{O}_{2}$ production are associated with interictal spikes. Inset (c) shows power spectral density (PSD) of selected "complex" (black) and "simple" (gray) spikes. B. All spontaneous seizures were preceded by a "complex" spike associated with a fast, high amplitude release of $\mathrm{H}_{2} \mathrm{O}_{2}$. Top: representative traces of field potential recordings (black) and associated extracellular $\mathrm{H}_{2} \mathrm{O}_{2}$ release (green). Inserts below shows field potential traces of selected seizures (black) with superimposed records (below) of LFP, $\mathrm{H}_{2} \mathrm{O}_{2}$ (green) and extracellular glutamate (red) corresponded to the seizure onset shown at expanded time scale. Note that the considerable difference in scale creates an illusion of "leading" $\mathrm{H}_{2} \mathrm{O}_{2}$ signal over the glutamate one. C. Dependence of $\mathrm{H}_{2} \mathrm{O}_{2}$ and glutamate releases versa amplitudes of the first (left) and the second (right) spikes in the complex spike potential. Note that both glutamate and $\mathrm{H}_{2} \mathrm{O}_{2}$ peaks were correlated with the amplitude of the second but not the first component in the spike complex. Insets show superimposed traces of field potential and $\mathrm{H}_{2} \mathrm{O}_{2}$ release, demonstrating strong dependence of this release on the second spike. D. Relationship between glutamate and $\mathrm{H}_{2} \mathrm{O}_{2}$ releases during the same epileptiform spikes. Note the correlation between these values. $\mathbf{E}$. Summary histogram of $\mathrm{H}_{2} \mathrm{O}_{2}$ release amplitudes during epileptiform spikes. Red line indicates a presumable threshold above which seizures are induced. 
Enhanced efficacy of both excitatory and inhibitory transmissions induced by 4-AP (19) resulted in hippocampal network hyperexcitability manifested as interictal activity (Fig. 1A). Interictal discharges displayed two major patterns which we defined either as "simple" or "complex" spikes (Fig. 1A: (a)-complex, (b)-simple). The complex spikes normally consisted of two or more closely spaced voltage peaks, while a "simple" spike was one peak only. All recorded spontaneous seizure-like events (SLEs) were preceded by a complex spike that was followed by DC shift (Fig. 1B, insets: arrows).

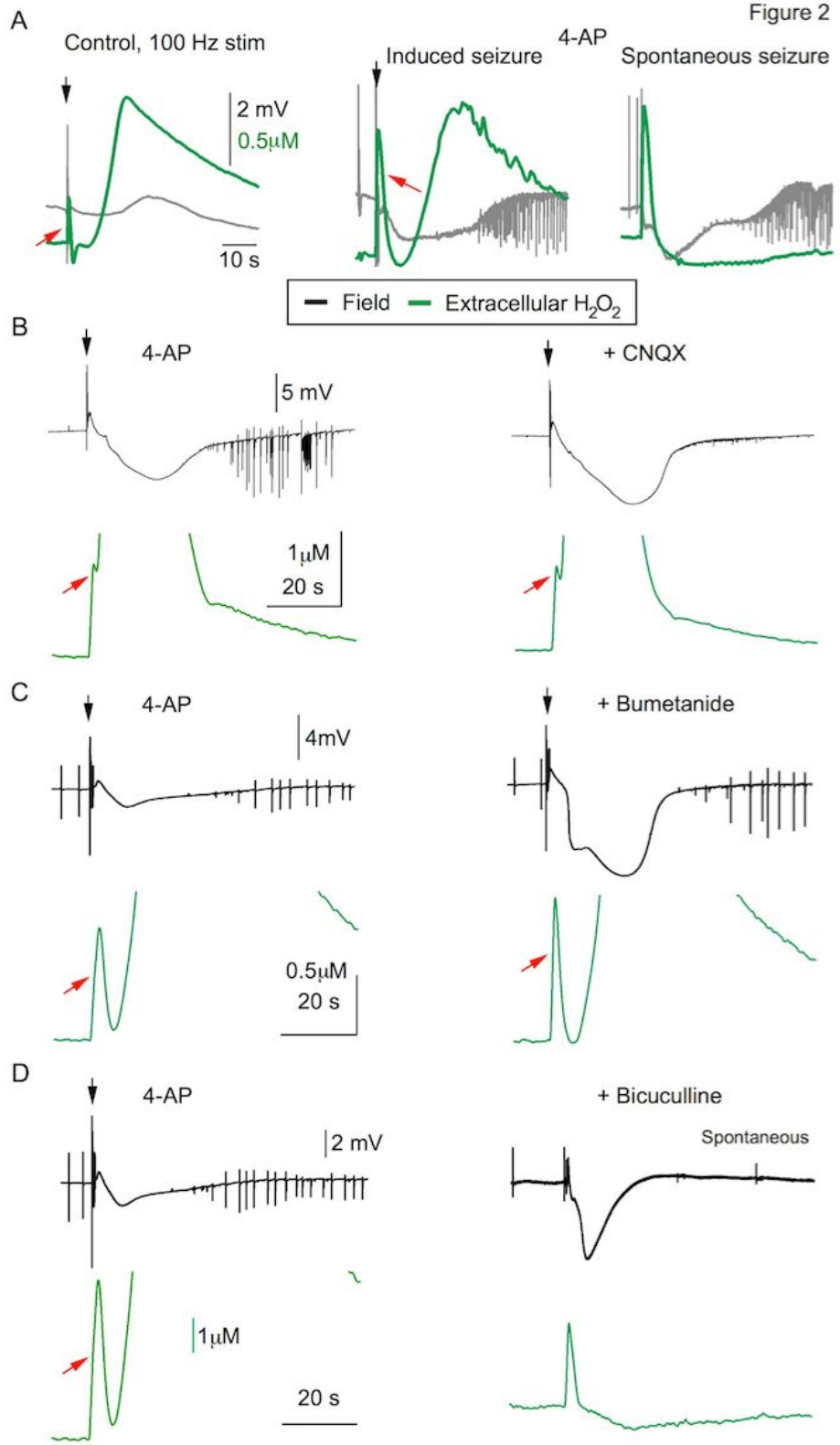

Fig. 2. $A M P A / K A$ receptor, $\mathrm{K}^{+}-C l$ co-transporters or $G A B A$ ergic transmission blockade does not prevent the DC-shift induction.

A. Superimposed records of field potential and $\mathrm{H}_{2} \mathrm{O}_{2}$ transients at $100 \mathrm{~Hz}, 1 \mathrm{~s}$ stimulation of Schaffer collaterals in control ACSF (left) and under 4-AP (induced seizure, middle), and during spontaneous seizure (right). Note that $\mathrm{H}_{2} \mathrm{O}_{2}$ release triggered by $100 \mathrm{~Hz}$ stimulation exhibits a biphasic shape characterized by an initial rapid peak (red arrows) followed by a delayed, slower and larger release. This second component was absent in case of spontaneous SLEs, therefore was not associated with seizure induction. B-D. Neither blockade of AMPA/kainate receptors $(\mathrm{B}, \mathrm{n}=4)$ nor blockade of $\mathrm{K}^{+}-\mathrm{Cl}^{-}$ co-transporters $(\mathrm{C}, \mathrm{n}=3)$ or inhibitory transmission $(\mathrm{D}$, $\mathrm{n}=3$ ) prevented the DC shift associated with rapid high release of $\mathrm{H}_{2} \mathrm{O}_{2}$. Note in (D) spontaneous seizure preceded by a complex spike with following DC shift despite the blockade of GABAergic transmission.

Simultaneous field (black), extracellular glutamate (red) and $\mathrm{H}_{2} \mathrm{O}_{2}$ (green) measurements (Fig. 1B, lower traces) revealed that the complex spikes were associated with an especially high and fast production of $\mathrm{H}_{2} \mathrm{O}_{2}$ as well as an augmented release of glutamate; both glutamate and $\mathrm{H}_{2} \mathrm{O}_{2}$ peaks were correlated with the amplitude of the second but not the first spike in the complex (Fig. 1C). Accordingly, the spike-induced $\mathrm{H}_{2} \mathrm{O}_{2}$ production was positively correlated with the release of glutamate (Fig. 1D). The distribution of $\mathrm{H}_{2} \mathrm{O}_{2}$ peaks induced by interictal activity (Fig. 1E) revealed a presumable threshold value (red line) for subsequent DC

shift and SLE initiation.

Taken together, these results suggest that SLE induction requires an interictal event of a specific profile - the complex spike - associated with suprathreshold release of $\mathrm{H}_{2} \mathrm{O}_{2}$. To investigate such a causal link, 
we replicated spontaneous SLEs using a $100 \mathrm{~Hz}$, 1s stimulation of Schaffer collaterals under 4-AP application (20). Spontaneous SLEs were observed in $44 \%$ of experiments, while synaptic stimulation successfully induced SLEs in each slice. In control ACSF, such stimulation normally resulted in an initial, rapid and small-amplitude production of $\mathrm{H}_{2} \mathrm{O}_{2}$ followed by a delayed (a few seconds) and a much larger but slow increase in extracellular $\mathrm{H}_{2} \mathrm{O}_{2}$ concentration (Fig. 2A, left, green trace). Since the last component was characteristic for the stimulation of Schaffer collaterals but was absent during spontaneous SLEs (Fig. 2A, right), its origin is likely related to the intracellular (mitochondrial) generation of reactive oxygen species (ROS) during en-masse activation of Schaffer collaterals. Therefore, we focused primary attention on the initial fast $\mathrm{H}_{2} \mathrm{O}_{2}$ transient presumably directly related to

A
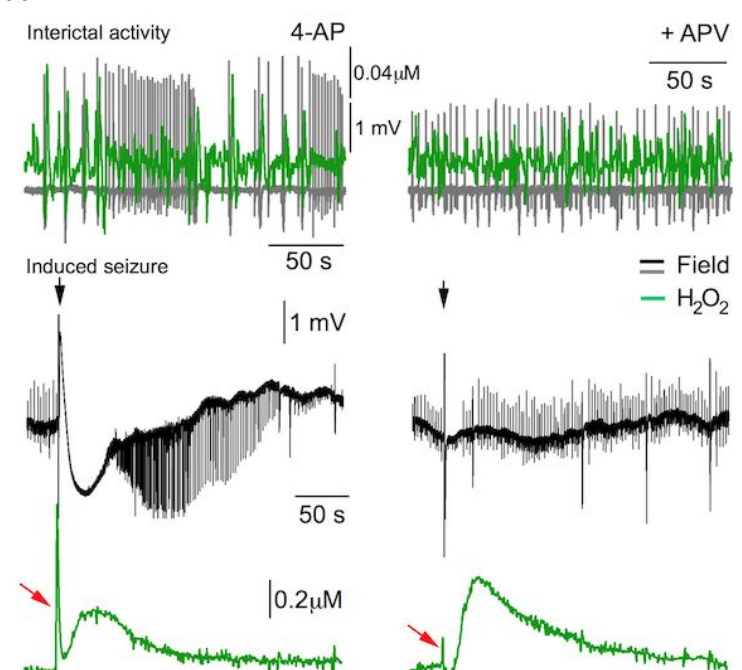

в
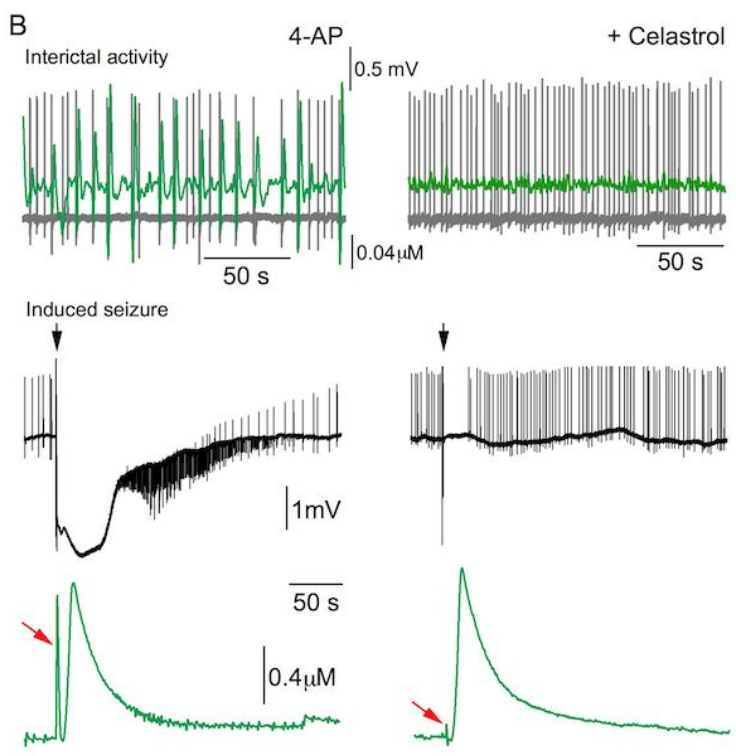

Figure 3
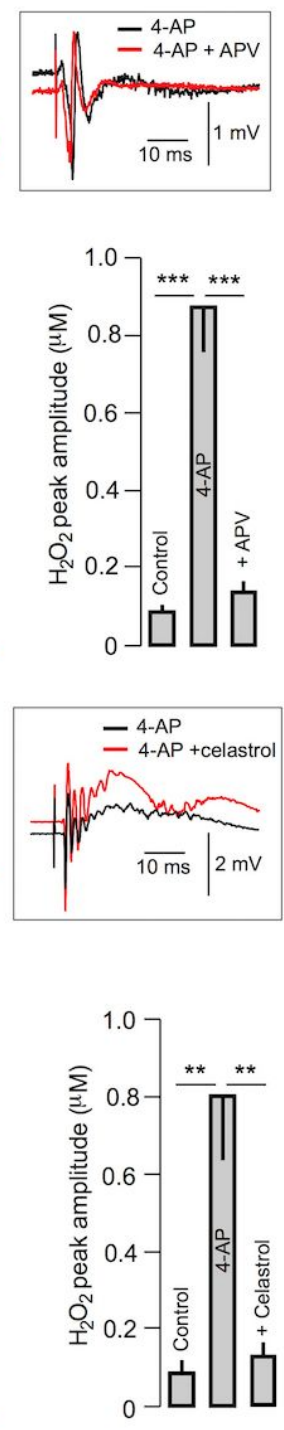

SLE induction. We also attempted to elucidate the origin of DC shift that is an inherent feature of SLEs.

Fig. 3. $\mathrm{NOX}$ antagonists ablate fast $\mathrm{H}_{2} \mathrm{O}_{2}$ production and prevent DC shift and seizure induction.

A-B. Upper traces: Decrease of interictal activity-associated release of $\mathrm{H}_{2} \mathrm{O}_{2}$ following inhibition of NOX. Superimposed records of field potential (gray) and $\mathrm{H}_{2} \mathrm{O}_{2}$ release (green) during interictal activity induced by 4-AP (left) and following addition of APV (A, right) or celastrol (B, right). Note that neither APV nor celastrol affected significantly LFP induced by a single stimulation of Schaffer collaterals (insets on the right). Lower traces: LFP and extracellular $\mathrm{H}_{2} \mathrm{O}_{2}$ transients at $100 \mathrm{~Hz}, 1 \mathrm{~s}$ stimulation of Schaffer collaterals under 4-AP. Blockade of NMDA receptors by APV (A) or of NOX by celastrol (B) abolished both the rapid $\mathrm{H}_{2} \mathrm{O}_{2}$ production (red arrows; $\mathrm{A}: \mathrm{n}=15 ; \mathrm{B}: \mathrm{n}=$ 7) and the associated DC shift.

Glutamate spillover during synaptic activity could potentially activate extra-synaptic receptors and thus induce secondary slow network depolarization resulting in the observed DC shift. However, application of CNQX $(40 \mu \mathrm{M})$, a potent antagonist of AMPA/KA receptors, inhibited the interictal activity but affected neither the fast $\mathrm{H}_{2} \mathrm{O}_{2}$ release nor the DC shift induced by synaptic stimulation (Fig. 2B). Indeed, CNQX prevents activation of postsynaptic AMPA/KA receptors, thus excluding the contribution of these receptors to the DC-shift. However, CNQX does not affect the presynaptic glutamate release during Schaffer collaterals stimulation, and 
presumably exactly this glutamate activates fast $\mathrm{H}_{2} \mathrm{O}_{2}$ release with a consequent induction of the DC-shift (see below).

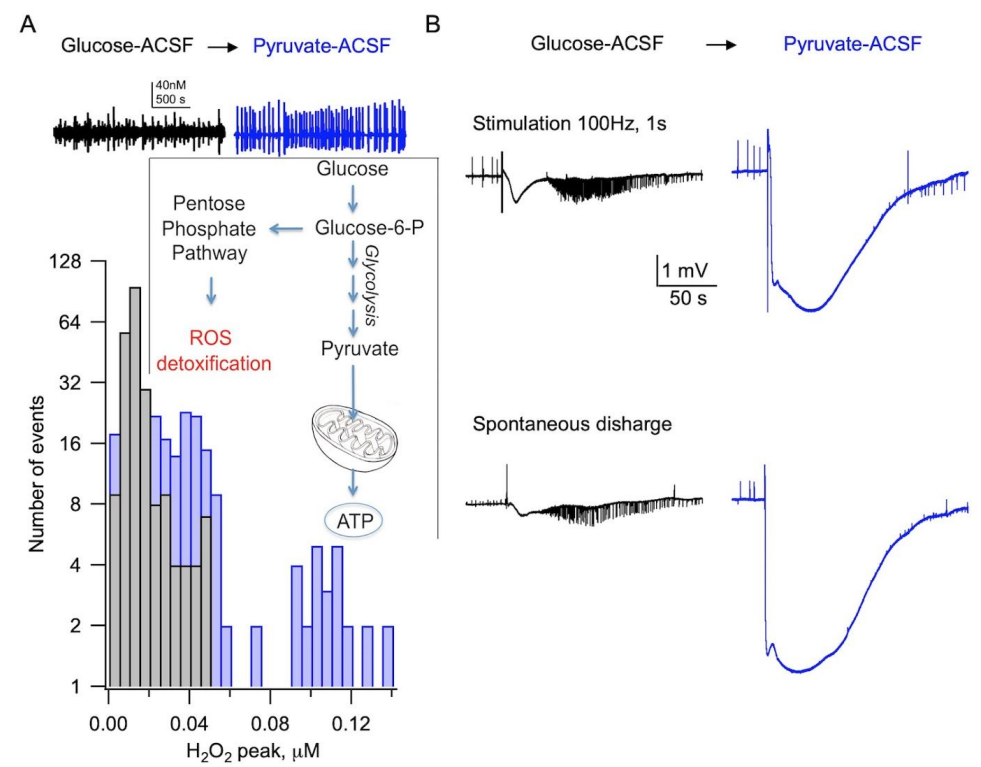

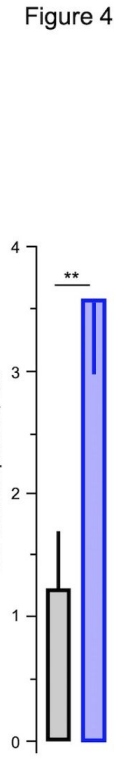

Fig. 4. Fast $\mathrm{H}_{2} \mathrm{O}_{2}$ release and DC shift magnitudes depend on the efficacy of cellular cytoplasmic antioxidant defense. A. Interictal activity-induced fast $\mathrm{H}_{2} \mathrm{O}_{2}$ release is increased following replacement of glucose for pyruvate in ACSF (see $\mathrm{H}_{2} \mathrm{O}_{2}$ release records above). In pyruvate-ACSF, mitochondria have sufficient fuel for generation of ATP, however intracellular cytoplasmic pentose phosphate pathway dependent antioxidant defense is diminished due to the absence of glucose (see schematic). B. The DC shift is significantly enhanced in pyruvate-ACSF $(n=12)$. Graph on the right demonstrates summary of the DC shift amplitude in glucose-ACSF and pyruvate-ASCF solutions.

Recent reports $(21,22)$ suggest $\mathrm{KCC} 2$ co-transporters as providers of enhanced extracellular $\mathrm{K}^{+}$ responsible for the DC shift during seizure initiation. However, application of a cation-chloride co-transporter's antagonist bumetanide $\left(50 \mu \mathrm{M}\right.$, similar to that used in (21)) failed to reduce $\mathrm{H}_{2} \mathrm{O}_{2}$ release and to prevent neither the DC shift nor SLE induction by stimulation $(\mathrm{n}=3$; Fig. $2 \mathrm{C})$. Note that bumetanide is not specific for the NKCC1 co-transporter only and at higher concentrations $(50 \mu \mathrm{M})$ also blocks KCC2 $(21,23)$. Finally, inhibition of GABAergic transmission by bicuculline $(20 \mu \mathrm{M})$ did not block spontaneous SLEs $(\mathrm{n}=3$; Fig. 2D) indicating that network synchronization by GABAergic neurotransmission is not mandatory for the SLE initiation.

Thus, neither activation of extrasynaptic AMPA/KA receptors nor GABAergic transmission turned to be primary players in the SLE onset. Therefore, we investigated the role of fast $\mathrm{H}_{2} \mathrm{O}_{2}$ release in the SLE initiation.

We supposed that rapid $\mathrm{H}_{2} \mathrm{O}_{2}$ production is underlain by the activation of NADPH oxidase (NOX), as NOX's unique biological function is to generate ROS (24); NOX is expressed in membranes of both neurons, astrocytes and microglia and the NMDA receptor-dependent signaling is one of NOX activation pathways $(24)^{(25)}$. Indeed, in our experiments a rise in extracellular glutamate preceding the SLE onset could be sufficient to activate NMDA receptors possessing high affinity to this neurotransmitter. Therefore, we tested the effects of NMDA or NOX antagonists on SLE generation. NMDA receptor blockade by APV did not prevent the interictal activity nor significantly affected synaptic transmission (Fig. 3A). Meanwhile, under APV rapid $\mathrm{H}_{2} \mathrm{O}_{2}$ production was substantially decreased during interictal events and was ablated at same stimulus that normally induced SLEs (Fig. $3 \mathrm{~A}$, red arrows). Importantly, APV prevented both the subsequent DC shifts and SLEs (in 14 of 15 experiments). Similarly, application of celastrol $(40 \mu \mathrm{M})$, a potent NOX antagonist (26), affected neither the interictal activity nor synaptic transmission (Fig. 3B), while the fast $\mathrm{H}_{2} \mathrm{O}_{2}$ production was inhibited during interictal events and was almost eliminated at $100 \mathrm{~Hz}$ stimulation. Celastrol also blocked the DC shifts and SLEs in 6 of 7 experiments. 

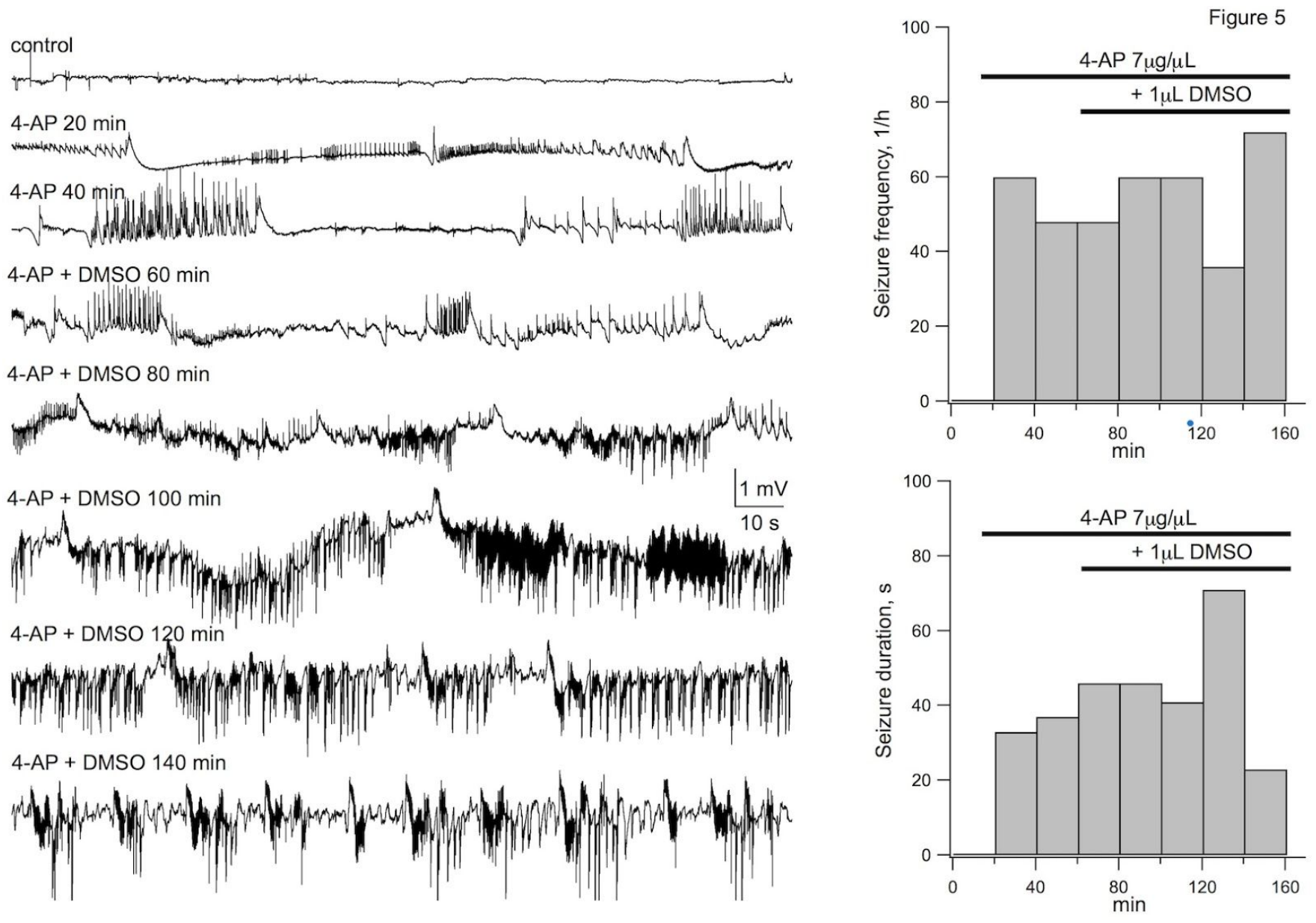

Fig. 5. Long-lasting hippocampal seizure activity induced in an anesthetized rat by intracerebroventricular 4-AP injection $(7 \mu \mathrm{g} / 1 \mu \mathrm{L})$. Corresponding dynamics of seizure frequency and duration (right). Injection of 4-AP induced seizure activity stable for at least 2 hours.

NMDA-NOX signaling role in SLE induction was further confirmed by brief direct application of NMDA onto CA1 stratum radiatum under 4-AP: NMDA-induced DC shifts and SLEs were observed (not shown; $\mathrm{n}=3$; see also (27)) and were also prevented by celastrol. We conclude, therefore, that NOX activation via NMDA receptor signaling triggers a cascade of events initiating the DC shift and the subsequent SLE.

Direct involvement of ROS in the process of SLE initiation and DC shift generation was further confirmed by the experiments with substitution of ACSF glucose with pyruvate that weakened the cytoplasmic antioxidant defense system (28) (see schematics in Fig. 4A). In pyruvate-ACSF, the fast $\mathrm{H}_{2} \mathrm{O}_{2}$ production during interictal events was significantly enhanced (Fig. 4A). Moreover, the DC shift during both the induced and spontaneous SLEs was increased (Fig. 4B), presumably due to higher extracellular $\mathrm{K}^{+}$concentration (28). 

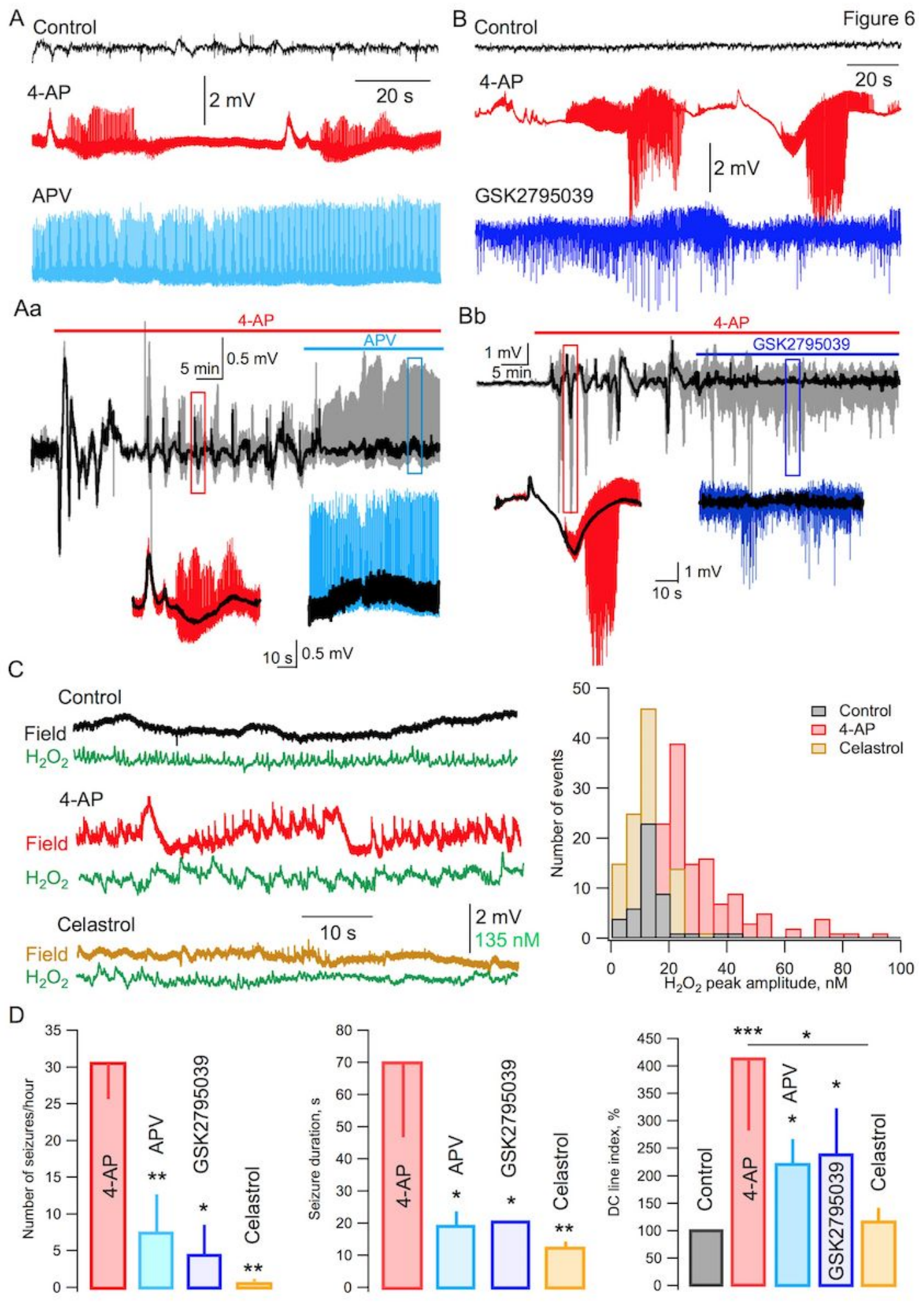
Fig. 6. NOX inhibition reduces seizure activity in vivo. A-C. LFP recordings in hippocampus of anesthetized rats. Intracerebroventricular injection of 4-AP induced regular ictal discharges (red, see also Fig. 5; $n=13$ ) that were suppressed by application of NMDA antagonist APV $(\mathrm{A} ; 4 \mu \mathrm{g} / 1 \mu \mathrm{L} ; \mathrm{n}=4)$ or by inhibition of NOX with GSK2795039 $(\mathrm{B} ; 45 \mu \mathrm{g} / 1 \mu \mathrm{L} ; \mathrm{n}=$ 5) or celastrol $(\mathrm{C} ; 72 \mu \mathrm{g} / 2 \mu \mathrm{L} ; \mathrm{n}=4)$. (Aa) and $(\mathbf{B b})$ demonstrate long-lasting field recordings (gray) with the inserted black traces representing field recordings low-pass filtered at $1 \mathrm{~Hz}$, that shows clearly ultra-slow baseline deviations during seizure activity. (C) also demonstrates extracellular $\mathrm{H}_{2} \mathrm{O}_{2}$ release (green) and distribution of $\mathrm{H}_{2} \mathrm{O}_{2}$ peak amplitudes. D. Summary of in vivo experiments. The DC line index represents the low-frequency deviation from the LFP baseline (see Methods).

\section{Acute seizures in vivo are prevented by NOX antagonists}

To verify the results obtained in slices we induced acute seizures in anesthetized rats by intracerebroventricular injection of 4-AP (29). Epileptic discharges started shortly (a few minutes) following 4-AP injection and lasted for more than two hours without decrementing (Fig. 5). We tested the efficacy of three NOX antagonists possessing different mechanisms of action $(30,31)$ - APV (25), celastrol (26) and GSK2795039 (31) on inhibition of seizures (Fig. 6). All three antagonists strongly reduced seizure activity (Fig. 6D). Importantly, GSK2795039 is a novel small molecule selective direct inhibitor of NOX2 with efficiency demonstrated in vivo and with brain bioavailability demonstrated at oral administration (31). Therefore, it possesses significant therapeutic potential for the development of anti-seizure medication.

A

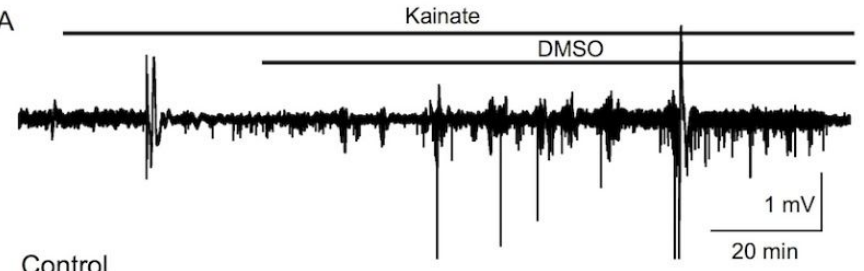

Control

KA 20 min

KA 40 min

KA+DMSO 60 min

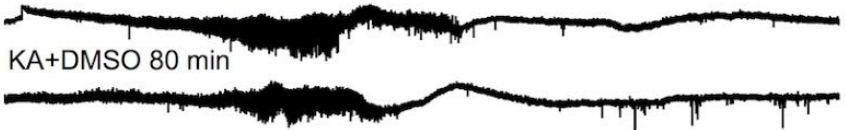

KA+DMSO 100 min
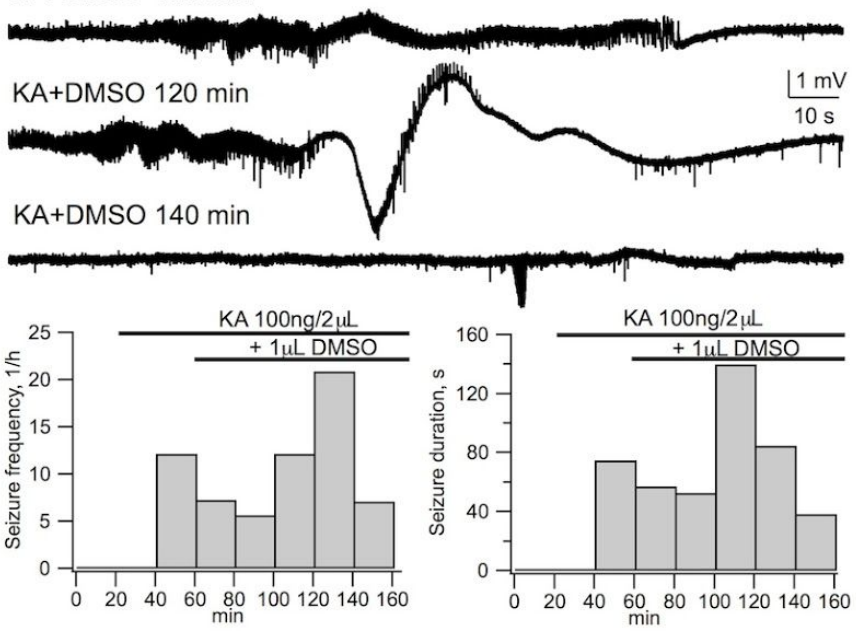

B

Figure 7

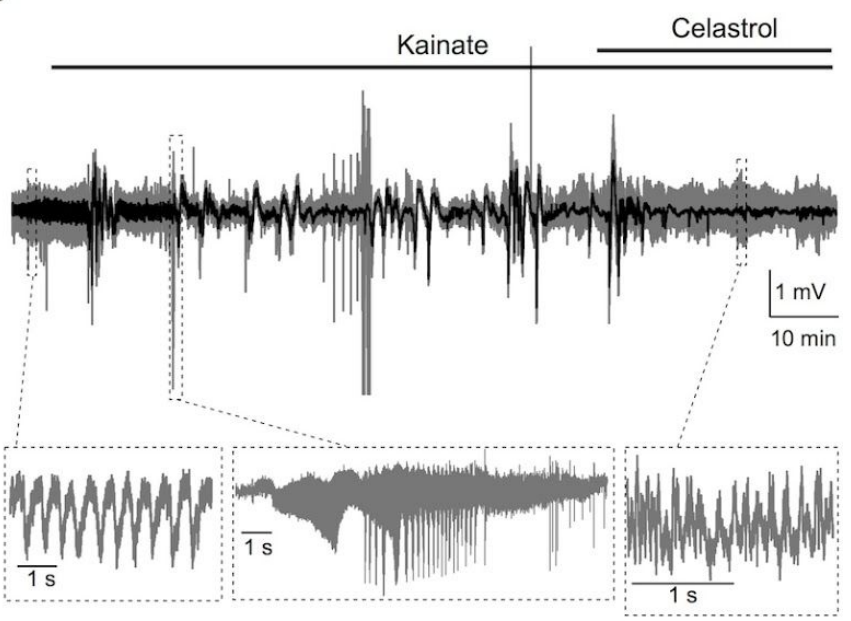

Control

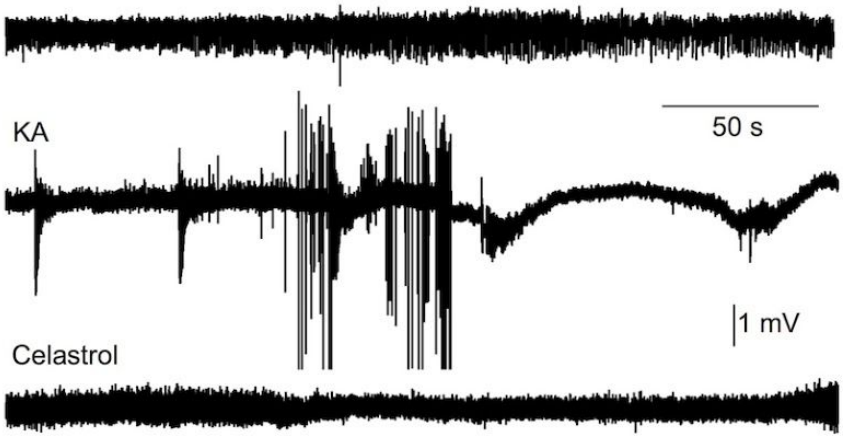


Fig. 7. A. Long-lasting hippocampal seizure activity induced in an anesthetized rat by intracerebroventricular kainate injection . B. Inhibition of kainate-induced seizures by celastrol $(72 \mu \mathrm{g} / 2 \mu \mathrm{L} ; \mathrm{n}=3)$. Upper trace demonstrates long-lasting field recordings (gray) with an inserted black trace representing field recording low-pass filtered at $1 \mathrm{~Hz}$, clearly showing ultra-slow baseline deviations during seizure activity.

To ensure that the NOX antagonists' anti-ictogenic effects are not specific for the 4-AP-induced seizures only, as an alternative we induced seizure activity by i.c.v. injection of kainate (KA). KA has been widely used to induce acute brain seizures via activation of KA receptors expressed in both neurons and astrocytes (32). In all experiments $(n=6)$, KA induced stable seizure activity (Fig. 7A). In three rats, celastrol was i.c.v. injected following the kainate-induced seizure activity: the average number of seizures under KA was $(9.6 \pm 1.85)$ /hour (average duration $27.6 \pm 3.07 \mathrm{~s})$; in all these slices seizure activity was completely abolished by application of celastrol (Fig. 7B). We conclude therefore that the NOX activation likely plays a dominating role in the onset of variety of acute seizures. The effects of NOX inhibitors on seizures during chronic epilepsy remain to be elucidated and are the issue of future studies.

\section{Discussion}

About $30 \%$ of patients with focal epilepsy are drug-resistant (2), thus pharmacoresistance remains one of the biggest challenges in epilepsy treatment. Understanding the mechanism of seizure onset is crucial for solving this problem. Although accumulation of ROS (oxidative stress) was implicated in epileptogenesis (33) and oxidative stress is in turn a consequence of seizures $(20,34)$, direct involvement of ROS in seizure initiation has never been demonstrated until now.

Here we provide the first evidence that the glutamate-induced and NMDA-mediated activation of NOX is the main trigger for seizures that are typical for focal epilepsies $(6,8)$. Importantly, NOX2 upregulation has been reported in surgical hippocampal specimens from a patient suffering from pharmacoresistant seizures (35). Although elucidation of the subsequent process of actual seizure generation is a matter of future studies, the available data allow us to propose the following sequence of events (Fig. 8B): NOX-induced oxidative stress transiently inhibits Na/K-ATPase (36), restricting the uptake of extracellular $\mathrm{K}^{+}$(increased by several $\mathrm{mM}$ at the very beginning of seizure initiation (19)) as well as the efflux of intracellular $\mathrm{Na}^{+}$, thus giving rise to focal network depolarization. The depolarization-induced additional $\mathrm{K}^{+}$release as well as astrocytic glutamate release (e.g. Fig. 8A; see also (37)) may further increase this depolarization. In addition, we observed significant tissue (astrocytic) swelling coincident at seizure onset with the sentinel spike (Fig. 8A; see also (38)) that can augment the extracellular $\mathrm{K}^{+}$/glutamate concentrations even further by reducing extracellular volume. Together, these events presumably underlie the DC shift. Pyramidal cell firing during the repolarization phase of the DC shift may underlie the network synchronization and following ictal discharges.

Considering the origin of complex spikes, interictal events initiating seizures may likely be induced by initial intensive spiking of interneurons. Indeed, in slices under 4-AP, a brief (30ms) optogenetic interneuron stimulation evoked the appearance of interictal-like events and suggested that activation of interneurons recruits and entrains pyramidal cells (39); some of these stimuli also induced ictal events (39-41). In vivo animals with acute 4-AP application, optogenetic interneuron stimulation during the interictal phase readily induced seizures both in neocortex (42) and hippocampus (39). Single-unit 
recordings revealed that the powerful ictogenic effect of interictal interneuron activation probably resulted from rebound firing enhancement of pyramidal neurons following the optogenetic interneuron stimulation. In chronic epileptic animals, interneurons were preferentially recruited during spontaneous interictal activity in the CA1 region (43), as well as before and during ictal events (44). In patients with mesial- temporal lobe epilepsy during the onset of LVF seizures in hippocampus, inhibitory neurons dramatically increased their firing rate prior to an increase in excitatory neuron firing (45).
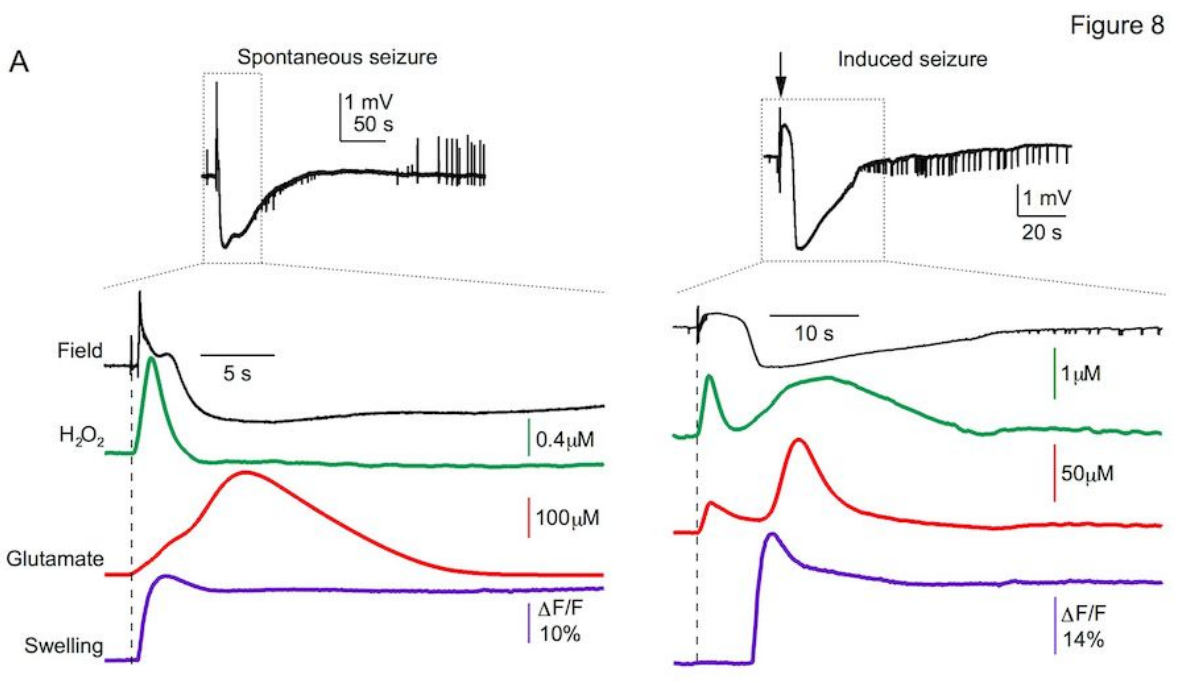

B

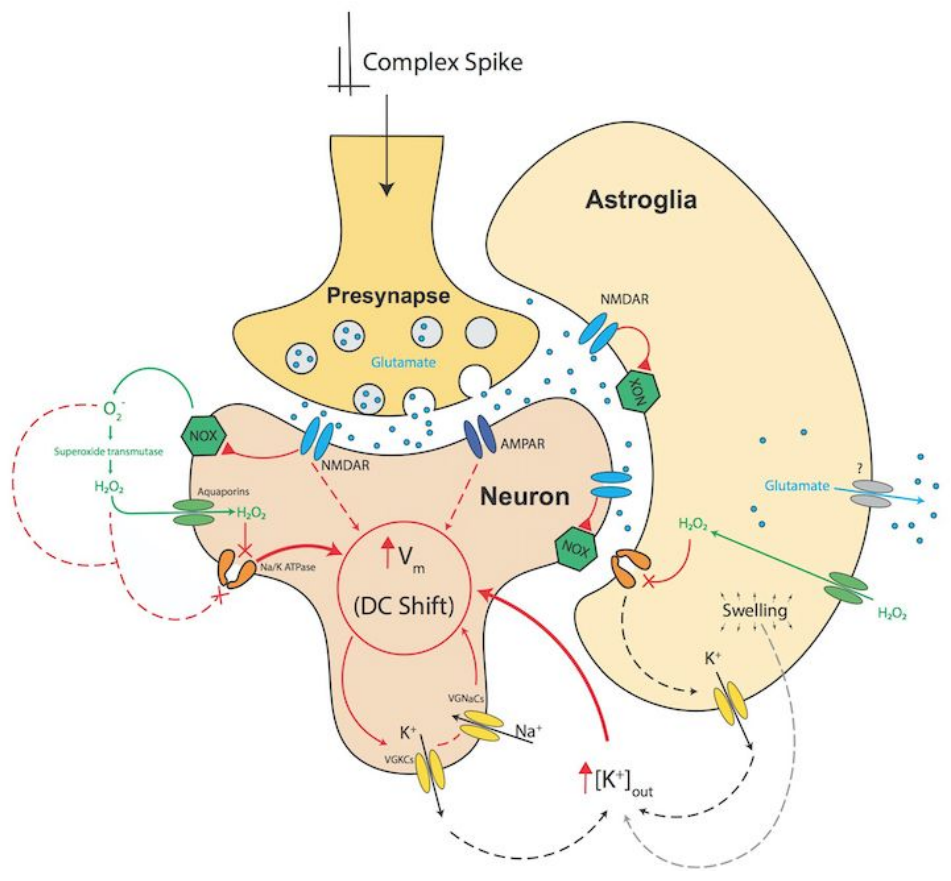

Fig. 8. Concurrent combination of several events is required for seizure induction.

A. Both spontaneous and induced seizures are associated with tissue swelling. B. Schematic representation of events during seizure induction. See the main text for details.

The general conclusion made from these data implies the dominating role of interneuron firing for the onset of both interictal and ictal events with the delayed pyramidal cell firing as the result of post-inhibition rebound excitation. In our case, one possible scenario for our observations is that the complex spikes represent the initial interneuron firing (first peak) with the second peak representing the delayed pyramidal cell firing with subsequent NOX activation and corresponding release of $\mathrm{H}_{2} \mathrm{O}_{2}$. Correlation of glutamate (as well as $\mathrm{H}_{2} \mathrm{O}_{2}$ ) release with the second peak amplitude but not with the first one validates such an assumption (Fig. 1C). Indeed, NOX2 is mainly expressed in pyramidal cells and microglia (46) while

considering interneurons, available (although very limited) data report highly low (almost below sensitivity threshold) and much smaller than in pyramidal cells NOX2 expression (47). Worth noting is that we did observe the "complex" (consisting of several peaks) spikes in the presence of bicuculline. However, inhibition of GABAergic transmission does not itself prevent the interneuron firing; in 
addition we have no evidence that these spikes have the same origin as those we observed in the presence of GABAergic transmission. As we suggested, enhanced pyramidal cell excitability due to the absence of inhibition may be involved in these spontaneous events.

Considering the relevance of the NOX antagonists utilized in our study for a clinical application, NMDA receptor antagonists, e.g., dizocilpine or ketamine, inhibited seizures in experimental animals evoked by pentetrazole, pilocarpine, maximal electroshock or sensory stimulation (48). However, NMDA receptor blockade can affect multiple brain functions and therefore chronic administration of NMDA receptor inhibitors, APV or its analogs, would likely lead to severe side effects. The therapeutic usefulness and anti-inflammatory properties of celastrol have been studied in several inflammatory diseases, including rheumatoid arthritis, ankylosing spondylitis, systemic lupus erythematosus, inflammatory bowel disease, osteoarthritis, allergy and skin inflammation (49). However, despite the therapeutic potential of celastrol, clinical applications are limited by low water solubility, reduced oral bioavailability, narrow window of dosage, and adverse side effects (50). In contrast, GSK2795039 is not cytotoxic at concentrations efficacious for NOX2 inhibition (31). It has been shown that GSK2795039 is orally available and can be measured in the blood and central nervous system, suggesting that it can cross the blood-brain barrier. It fully inhibited NOX2 enzyme activity in vivo following systemic dosing in mice, while GSK2795039 effects were reversible since $24 \mathrm{~h}$ after administration. GSK2795039 was well tolerated by rodents, with no obvious adverse effects following 5 days of oral administration. However, the up to date information on GSK2795039 pharmacology is limited and the drug's in vivo safety, pharmacokinetics and pharmacodynamics should be evaluated further in future studies.

While considering the principal role of NOX-induced oxidative stress in seizure initiation, it is also important to note a failure of exogenous antioxidants to affect the fast $\mathrm{H}_{2} \mathrm{O}_{2}$ release. Indeed, as we demonstrated previously (20), neither Tempol nor apocynin (potent antioxidants) significantly affected the fast $\mathrm{H}_{2} \mathrm{O}_{2}$ transient, indicating that anti-seizure drug development should focus either on the enhancement of endogenous antioxidant defense and/or on direct antagonists of NOX. In addition, as expected, direct application $\mathrm{H}_{2} \mathrm{O}_{2}$ to quiescent slices either in ACSF perfusate or as short-lasting puffs (data not shown, see (20)) failed to replicate the effects of NOX activation (the DC shift), indicating that a concurrent combination of several events, e.g. glutamate release and spillover inducing NOX activation and excessive release of $\mathrm{K}^{+}$(see Fig. 8B) might be required for seizure induction.

In summary, our present results reveal a specific trigger mechanism for seizure onset as well as ways to block it and thus to prevent seizures, with major implications for epilepsy treatment.

Acknowledgements: This work was supported by grants RSF 17-75-20245 (AM) and ERA SynBIO grant MODULIGHTOR, PCIN-2015-163-C02-01 (PB).

\section{Author Contributions}

AM, AI, PB, MZ, and YZ contributed to study concept and design. AM, AI, AL, MZ and YZ contributed to data acquisition and analysis. MZ and YZ drafted the study and figures.

Potential Conflicts of Interest: Nothing to report. 


\section{References}

1. K. S. Wilcox et al., Issues related to development of new antiseizure treatments. Epilepsia. 54 Suppl 4, 24-34 (2013).

2. F. Tang, A. M. S. Hartz, B. Bauer, Drug-Resistant Epilepsy: Multiple Hypotheses, Few Answers. Front. Neurol. 8, 301 (2017).

3. D. Schmidt, M. Sillanpaa, Evidence-based review on the natural history of the epilepsies. Curr. Opin. Neurol. 25, 159-163 (2012).

4. W. Loscher, H. Klitgaard, R. E. Twyman, D. Schmidt, New avenues for anti-epileptic drug discovery and development. Nat. Rev. Drug Discov. 12, 757-776 (2013).

5. P. Perucca, F. Dubeau, J. Gotman, Intracranial electroencephalographic seizure-onset patterns: effect of underlying pathology. Brain. 137, 183-196 (2014).

6. A. Bragin et al., Analysis of initial slow waves (ISWs) at the seizure onset in patients with drug resistant temporal lobe epilepsy. Epilepsia. 48, 1883-1894 (2007).

7. K. Kanazawa et al., Intracranially recorded ictal direct current shifts may precede high frequency oscillations in human epilepsy. Clin. Neurophysiol. 126, 47-59 (2015).

8. W. Kim, J. W. Miller, J. G. Ojemann, K. J. Miller, Ictal localization by invasive recording of infraslow activity with DC-coupled amplifiers. J. Clin. Neurophysiol. 26, 135-144 (2009).

9. V. Gnatkovsky et al., Biomarkers of epileptogenic zone defined by quantified stereo-EEG analysis. Epilepsia. 55, 296-305 (2014).

10. A. Ikeda et al., Focal ictal direct current shifts in human epilepsy as studied by subdural and scalp recording. Brain. 122 ( Pt 5), 827-838 (1999).

11. T. L. Eissa et al., Multiscale Aspects of Generation of High-Gamma Activity during Seizures in Human Neocortex. eNeuro. 3 (2016), doi:10.1523/ENEURO.0141-15.2016.

12. M. Avoli et al., Synchronous GABA-mediated potentials and epileptiform discharges in the rat limbic system in vitro. J. Neurosci. 16, 3912-3924 (1996).

13. M. S. Jensen, Y. Yaari, The relationship between interictal and ictal paroxysms in an in vitro model of focal hippocampal epilepsy. Ann. Neurol. 24, 591-598 (1988).

14. A. Leschinger, J. Stabel, P. Igelmund, U. Heinemann, Pharmacological and electrographic properties of epileptiform activity induced by elevated $\mathrm{K}+$ and lowered $\mathrm{Ca} 2+$ and $\mathrm{Mg} 2+$ concentration in rat hippocampal slices. Exp. Brain Res. 96, 230-240 (1993).

15. M. D'Antuono et al., GABAA receptor-dependent synchronization leads to ictogenesis in the 
human dysplastic cortex. Brain. 127, 1626-1640 (2004).

16. S. Gabriel et al., Stimulus and potassium-induced epileptiform activity in the human dentate gyrus from patients with and without hippocampal sclerosis. J. Neurosci. 24, 10416-10430 (2004).

17. S. Z. Reyes-Garcia et al., Different patterns of epileptiform-like activity are generated in the sclerotic hippocampus from patients with drug-resistant temporal lobe epilepsy. Sci. Rep. 8, 7116 (2018).

18. P. Jiruska et al., Update on the mechanisms and roles of high-frequency oscillations in seizures and epileptic disorders. Epilepsia. 58, 1330-1339 (2017).

19. M. Avoli, M. de Curtis, GABAergic synchronization in the limbic system and its role in the generation of epileptiform activity. Prog. Neurobiol. 95, 104-132 (2011).

20. A. Malkov et al., Seizure-induced reduction in glucose utilization promotes brain hypometabolism during epileptogenesis. Neurobiol. Dis. 116, 28-38 (2018).

21. S. Hamidi, M. Avoli, KCC2 function modulates in vitro ictogenesis. Neurobiol. Dis. 79, 51-58 (2015).

22. O. C. González et al., Role of KCC2-dependent potassium efflux in 4-Aminopyridine-induced Epileptiform synchronization. Neurobiol. Dis. 109, 137-147 (2018).

23. W. Löscher, M. Puskarjov, K. Kaila, Cation-chloride cotransporters NKCC1 and KCC2 as potential targets for novel antiepileptic and antiepileptogenic treatments. Neuropharmacology. 69, 62-74 (2013).

24. S. Sorce et al., NADPH oxidases as drug targets and biomarkers in neurodegenerative diseases: What is the evidence? Free Radic. Biol. Med. 112, 387-396 (2017).

25. S. Kovac et al., Metabolic and Homeostatic Changes in Seizures and Acquired Epilepsy-Mitochondria, Calcium Dynamics and Reactive Oxygen Species. Int. J. Mol. Sci. 18 (2017), doi:10.3390/ijms18091935.

26. V. Jaquet et al., NADPH oxidase (NOX) isoforms are inhibited by celastrol with a dual mode of action. Br. J. Pharmacol. 164, 507-520 (2011).

27. G. Losi et al., A brain slice experimental model to study the generation and the propagation of focally-induced epileptiform activity. J. Neurosci. Methods. 260, 125-131 (2016).

28. A. Malkov et al., Reactive oxygen species initiate a metabolic collapse in hippocampal slices: potential trigger of cortical spreading depression. J. Cereb. Blood Flow Metab. 34, 1540-1549 (2014).

29. A. Morales-Villagran, M. E. Urena-Guerrero, R. Tapia, Protection by NMDA receptor antagonists against seizures induced by intracerebral administration of 4-aminopyridine. Eur. J. Pharmacol. 
305, 87-93 (1996).

30. S. Altenhofer, K. A. Radermacher, P. W. Kleikers, K. Wingler, H. H. Schmidt, Evolution of NADPH Oxidase Inhibitors: Selectivity and Mechanisms for Target Engagement. Antioxid. Redox Signal. 23, 406-427 (2015).

31. K. Hirano et al., Discovery of GSK2795039, a Novel Small Molecule NADPH Oxidase 2 Inhibitor. Antioxid. Redox Signal. 23, 358-374 (2015).

32. R. Falcón-Moya, T. S. Sihra, A. Rodríguez-Moreno, Kainate Receptors: Role in Epilepsy. Front. Mol. Neurosci. 11, 217 (2018).

33. J. N. Pearson-Smith, M. Patel, Metabolic Dysfunction and Oxidative Stress in Epilepsy. Int. J. Mol. Sci. 18 (2017), doi:10.3390/ijms18112365.

34. S. Puttachary, S. Sharma, S. Stark, T. Thippeswamy, Seizure-Induced Oxidative Stress in Temporal Lobe Epilepsy. Biomed Res. Int. 2015, 745613 (2015).

35. A. Pecorelli et al., NADPH oxidase activation and 4-hydroxy-2-nonenal/aquaporin-4 adducts as possible new players in oxidative neuronal damage presents in drug-resistant epilepsy. Biochim. Biophys. Acta. 1852, 507-519 (2015).

36. X. Q. Wang et al., Apoptotic insults impair $\mathrm{Na}+, \mathrm{K}+$-ATPase activity as a mechanism of neuronal death mediated by concurrent ATP deficiency and oxidant stress. J. Cell Sci. 116, 2099-2110 (2003).

37. G. F. Tian et al., An astrocytic basis of epilepsy. Nat. Med. 11, 973-981 (2005).

38. Z. Zador, R. Weiczner, A. Mihaly, Long-lasting dephosphorylation of connexin 43 in acute seizures is regulated by NMDA receptors in the rat cerebral cortex. Mol. Med. Rep. 1, 721-727 (2008).

39. M. Chang et al., Brief activation of GABAergic interneurons initiates the transition to ictal events through post-inhibitory rebound excitation. Neurobiol. Dis. 109, 102-116 (2018).

40. L. Yekhlef, G. L. Breschi, L. Lagostena, G. Russo, S. Taverna, Selective activation of parvalbumin- or somatostatin-expressing interneurons triggers epileptic seizurelike activity in mouse medial entorhinal cortex. J. Neurophysiol. 113, 1616-1630 (2015).

41. Z. Shiri, F. Manseau, M. Lévesque, S. Williams, M. Avoli, Interneuron activity leads to initiation of low-voltage fast-onset seizures. Ann. Neurol. 77, 541-546 (2015).

42. F. Assaf, Y. Schiller, The antiepileptic and ictogenic effects of optogenetic neurostimulation of PV-expressing interneurons. J. Neurophysiol. 116, 1694-1704 (2016).

43. S. F. Muldoon et al., GABAergic inhibition shapes interictal dynamics in awake epileptic mice. 
Brain. 138, 2875-2890 (2015).

44. A. R. Neumann et al., Involvement of fast-spiking cells in ictal sequences during spontaneous seizures in rats with chronic temporal lobe epilepsy. Brain. 140, 2355-2369 (2017).

45. B. Elahian et al., Low-Voltage Fast Seizures in Humans Begin with Increased Interneuron Firing. Ann. Neurol. (2018), doi:10.1002/ana.25325.

46. Z. Nayernia, V. Jaquet, K.-H. Krause, New insights on NOX enzymes in the central nervous system. Antioxid. Redox Signal. 20, 2815-2837 (2014).

47. S. Schiavone et al., NADPH oxidase elevations in pyramidal neurons drive psychosocial stress-induced neuropathology. Transl. Psychiatry. 2, e111 (2012).

48. W. Lasoń, M. Chlebicka, K. Rejdak, Research advances in basic mechanisms of seizures and antiepileptic drug action. Pharmacol. Rep. 65, 787-801 (2013).

49. R. Cascão, J. E. Fonseca, L. F. Moita, Celastrol: A Spectrum of Treatment Opportunities in Chronic Diseases. Front. Med. 4, 69 (2017).

50. J. Zhang et al., Oral bioavailability and gender-related pharmacokinetics of celastrol following administration of pure celastrol and its related tablets in rats. J. Ethnopharmacol. 144, 195-200 (2012). 